East African Medical Journal Vol. 77 No. 9 September 2000

MANAGEMENT OF UNDESCENDED TESTES IN CHILDREN IN ZARIA, NIGERIA

E. A. Ameh, MBBS, FWACS, Lecturer and Consultant and H. N. Mbibu, MBBS, FWACS, Lecturer and Consultant, Paediatric Surgery and Urology Units, Department of Surgery, Ahmadu Bello University Teaching Hospital, Zaria, Nigeria.

Request for reprints to: Dr. E. A. Ameh, Paediatric Surgery Unit, Department of Surgery, ABU Teaching Hospital, Zaria, Nigeria.

\title{
MANAGEMENT OF UNDESCENDED TESTES IN CHILDREN IN ZARIA, NIGERIA
}

\author{
E. A. AMEH and H. N. MBIBU
}

\begin{abstract}
Objective: To study the presentation, management and outcome of undescended testes in children in a northern Nigerian population.

Design: Retrospective study.

Setting: Ahmadu Bello University Teaching Hospital, Zaria, Nigeria.

Subjects: Thirty six children aged $\leq 12$ years with 43 undescended testes managed in 10 years. Interventions: Orchidopexy, orchidectomy, herniotomy.

Results: The age at surgery was fourteen months to 12 years (median six years); four (11\%) had correction before two years, $15(42 \%)$ before five years and $21(57 \%)$ at age $\geq 5$ years. Thirty two $(74 \%)$ testes were palpable and eleven $(26 \%)$ non-palpable. Evaluation was mainly clinical. Ultrasonography was performed for three non-palpable testes but was not helpful. Laparoscopy was not used in any patient. The condition was unilateral in $29(81 \%)$ and bilateral in seven (19\%). Forty five per cent of the testes were in the inguinal canal, 31\% at the external ring, and $12 \%$ each at the internal ring and abdomen respectively. Ten (24\%) testes were macroscopically atrophic (canalicular five, abdominal four, internal ring one). Orchidopexy was performed for 37 undescended testes and orchidectomy for four. Groin and scrotal haematoma developed following one orchidopexy. Following orchidopexy, four $(10 \%)$ testes retracted necessitating repeat surgery.

Conclusion: There is a need to educate parents, traditional birth attendants, midwives and doctors in our environment to ensure earlier presentation and treatment.
\end{abstract}

\section{INTRODUCTION}

Reports on undescended testes in African children are few $(1,2)$ but the condition is not rare and diagnosis is often delayed. In 1986, Mabogunje(1) reported on undescended testes in the Zaria area of northern Nigeria in which $75 \%$ presented after five years. In Tanzania(2), $57.5 \%$ of patients with undescended testes were operated after five years. This is a report of the current trend of undescended testes in Zaria, northern Nigeria.

\section{MATERIALS AND METHODS}

In the ten years, 1988-1997, forty four children aged $\leq 12$ years were managed for undescended testes by paediatric surgeons and urologists at the Ahmadu Bello University Teaching Hospital, Zaria, Nigeria. Thirty six patients had adequate records for inclusion in the study and have been retrospectively reviewed.

\section{RESULTS}

The thirty six children had 43 undescended testes. Twenty patients $(56 \%)$ presented as a result of empty scrotum noticed since birth, $14(39 \%)$ due to groin swelling and two $(6 \%)$ due to pain.
Age at surgery: The age at surgery was fourteen months to 12 years (median six years). Four patients (11\%) had correction before two years, $15(42 \%)$ before five years and $21(58 \%)$ at age $\geq 5$ years (Table 1$)$. Ten patients $(28 \%)$ had first contact with medical personnel at peripheral clinics and hospitals before two years but the parents were only reassured. In one patient, the initial attending surgeons due to a congenital heart disease avoided treatment, and the patient later presented to our hospital at 12 years.

Table 1

Age at operation for undescended testes in 36 children

\begin{tabular}{ll}
\hline Age (years) & No. $(\%)$ \\
\hline$<2$ & $4(11)$ \\
$2-4$ & $11(31)$ \\
$5-9$ & $14(39)$ \\
$10-12$ & $7(19)$ \\
\hline Total & $36(100)$ \\
\hline
\end{tabular}

Evaluation: An experienced senior registrar or consultant usually examined the patients. Thirty two of the 43 undescended testes $(74 \%)$ were palpable along the line of descent while eleven $(26 \%)$ were impalpable. 
Ultrasonography was performed for three impalpable testes but the testes were not seen. Laparoscopy was not available for use in any patient.

Laterality and level of descent: Testicular undescent was right sided in fifteen patients $(42 \%)$, left fourteen (39\%) and bilateral seven (19\%). The penis was normal in all who had bilateral undescent.

The operative findings are summarised in Table 2. Forty two undescended testes were operated upon, of which nineteen $(45 \%)$ were situated in the inguinal canal, thirteen $(31 \%)$ external ring (one was impalpable clinically) and five $(12 \%)$ each at level of internal ring and intraabdominal respectively.

Table 2

Level of descent and gross appearance of 42 undescended testes

\begin{tabular}{llll}
\hline Level of descent & Normal & $\begin{array}{l}\text { No. } \\
\text { atrophy }\end{array}$ & $\begin{array}{l}\text { Total } \\
(\%)\end{array}$ \\
\hline Canalicular & 14 & 5 & $19(45)$ \\
External ring & 13 & - & $13(31)$ \\
Internal ring & 4 & 1 & $5(20)$ \\
Abdominal & 1 & 4 & $5(20)$ \\
\hline Total $(\%)$ & $32(76)$ & $10(24)$ & $42(100)$
\end{tabular}

Five patients (aged five to nine years) with canalicular testes had macroscopically atrophic testes, as did four (aged four to twelve years) with abdominal testes and one (two years) with the testes at the level of the internal ring.

Associated hernia sacs were found with $22(52 \%)$ testes, five $(23 \%)$ of which testes were atrophic (canalicular four, abdominal one). Thirteen of the hernias were leftsided and nine right.

Treatment: Orchidopexy was performed for 37 undescended testes and in four, orchidectomy was necessitated by severe atrophy (age 4-12 years, abdominal three, canalicular one). Of the seven bilateral cases, three had bilateral orchidopexy at the same sitting and one at six months interval. In one 12 year old with bilateral abdominal testes, both could not reach the internal ring after mobilisation; the right testis, which was severely atrophic, was excised. Two other patients (six and seven years old) never returned for orchidopexy after initial orchidopexy on the opposite side. Associated hernias were repaired. Human chorionic gonadotropin was not used in any patient. Histology of the excised testes showed various degrees of atrophic changes.

Outcome: Thirteen patients (36\%) were followed up for one to six years; others were lost to follow up. One sixyear old had groin and scrotal haematoma following orchidopexy for canalicular testis, which resolved on conservative management. Four $(10 \%)$ testes retracted four months following orchidopexies (two at internal ring, one canalicular, one external ring); one of these had repeat orchidopexy without complications, one is awaiting repeat orchidopexy and two were lost to follow up.

\section{DISCUSSION}

Undescended testis is a condition of great concern to paediatric surgeons and urologists owing to the risk of impaired spermatogenesis and consequent infertility later in life. The risk of testicular cancer may be higher in these patients as noted by one report in which ten per cent of patients with testicular cancer gave a history of cryptorchidism, even though there appears to be no conclusive proof that correction of cryptorchidism protects against cancer(3), but renders the testis easily accessible.

To avoid the risk of testicular atrophy and infertility, it is now widely agreed that orchidopexy be performed at age $\leq 2$ years(3-5). In the present report, however, only $11 \%$ had orchidopexy before two years and $42 \%$ before five years. Majority (58\%) had correction after five years, by which time significant morphological changes would have occurred in the testis. This finding is similar to a report from Dar es Salaam, Tanzania(2) in which $42.5 \%$ had surgery by five years. In an earlier report from Zaria(1), only $25 \%$ of children and adults with undescended testes had surgery by five years. In a report from Ireland(6), the mean age at surgery was 9.5 years but this gradually decreased over the years. In our environment, the current median age at surgery is six years; the reasons for this delay include, late presentation, ignorance of initial attending doctors regarding age at optimal treatment and lack of recognition by midwives. To improve on the age at surgery, it is necessary to educate parents, midwives and doctors as suggested before $(1,2)$. Since many deliveries take place in the traditional home setting, traditional birth attendants should also be taught palpation of the scrotum at birth and refer any suspicious case to a hospital early.

As in previous reports from tropical Africa(1,2), canalicular testes are the most common in this report. Overall, 11 (26\%) testes were impalpable. The location of the impalpable testes frequently poses a challenge. Ultrasonography gives false negative rates as high as 50\% and is believed not to be any better than careful examination by an experienced surgeon(7). To date, the most reliable diagnostic method for the impalpable testes is laparoscopy(7-11) and definitive treatment is possible at laparoscopy in 50\%(7). In our environment, only ultrasound is available and it did not locate the testis in any of the three patients who had it; operative exploration of the groin and retroperitoneal space is therefore performed in all our patients with impalpable testes using the extraperitoneal $\operatorname{approach}(12)$.

Overall, ten $(28 \%)$ patients $(24 \%$ of undescended testes) in this report, aged two to twelve years (median 7.5 years) had testicular atrophy compared to $12.8 \%(86 \%>5$ years) in Tanzania(2). Orchidopexy was possible in $88 \%$ of the undescended testes in this report but none of the five abdominal testes could reach the scrotum at one stage. In four patients aged four to twelve years (abdominal three, canalicular one), orchidectomy was performed for severe atrophy. One report has noted that $69 \%$ of abdominal and $94 \%$ of canalicular testes can reach the scrotum(13). It has 
also been suggested that a unilateral undescended testes be removed in a normal male over sixteen years of age(14) and orchidectomy may be the best treatment for an abdominal testis if the opposite testis is normal(3). Following orchidopexy, four of 37 (11\%) testes retracted necessitating repeat orchidopexy. Obviously, one-stage procedure was unsuitable in these patients or mobilisation was inadequate. A staged procedure or the Fowler-Stephens manouevre(3) may have been more appropriate.

It has been shown that fertility after treatment for unilateral undescended testis is about $84 \%$, bilateral $60 \%$ and overall $79 \%(15)$. That report noted that fertility is poor for bilateral undescended testis if treated after 18 years. About $10 \%$ of patients with testicular cancer may give a history of cryptorchidism(3). In the present report, fertility and cancer rate cannot be ascertained. There is a need to conduct further studies on undescended testes in our environment and also improve the facilities available for evaluation. Education of traditional birth attendants, midwives, obstetricians and other doctors and parents need to be continuously emphasised to ensure early presentation and treatment.

\section{REFERENCES}

1. Mabogunje O.A. Surgery for undescended testes. East Afr. Med. J. 1986; 63:251-257.

2. Mlay S.M. and Sayi E.N. Undescended testes in paediatric patients at Muhimbili medical center, Dar es Salaam. East Afr. Med. J. 1994; 71:135-137.

3. Gough M.H. Cryptorchidism. Brit. J Surg. 1989; 76:109-112.

4. Campbell J.R. Undescended testes. In: Paediatric Surgery, Ashcraft K.W, Holder T.M. (eds), WB Saunders Company, Philadelphia. 1993, pp589-594.

5. Bianchi A. The undescended. In: Paediatric Surgery, Atwell J.D. (ed), Arnold, London, 1998, pp327-337.

6. McKienan M.V., Murphy P.D. and Johnston J.G. Ten-year review of treatment of undescended testes in the west of Ireland. Brit. J. Urol. 1992; 70:84-89.

7. Cortes D., Thorup J.M., Lenz K., Beck B.L. and Nielsen O.H. Laparoscopy in 100 consecutive patients with 128 impalpable testes. Brit. J. Urol. 1995; 75:281-287.

8. Perovic S. and Janic N. Laparoscopy in the diagnosis of nonpalpable testes. Brit. J. Urol. 1994; 73:310-313.

9. Guiney E.J., Corbally M. and Malone P.S. Laparoscopy and the management of the impalpable testis. Brit. J Urol. 1989; 63:313316.

10. Nassar A.H.M. Laparoscopic - assisted orchidopexy. a new approach to the impalpable testis. J. Paediat. Surg. 1995; 30:39-41.

11. Scott J.E.S. Laparoscopy as an aid in the diagnosis and management of the impalpable testis. J. Paediat. Surg. 1982; 17:14-16.

12. Jones P.F. and Bagley F.H. An abdominal extraperitoneal approach for difficult cases. Brit. J. Surg. 1979; 66:14-18.

13. Saw K.C., Eardley I., Dennis M.J.S. and Whitaker R.H. Surgical outcome of orchidopexy I: previously unoperated testes. Brit. J. Urol. 1992; 70:90-94.

14. Whitaker R.H. Undescended testis- the need for standard classification. Brit. J. Urol. 1992; 70:1-6.

15. Kumar D., Bremner D.N. and Brown P.W. Fertility after orchidopexy for cryptorchidism: a new approach to assessment. Brit. J. Urol. 1993; 73:516-520. 